\title{
Storytelling among child welfare social workers: constructing professional role and resilience through team talk
}

\begin{abstract}
Child welfare social work is emotive and demanding work, requiring highly-skilled and resilient practitioners. In a context of austerity, increased public scrutiny and accountability, defensive practice has been identified as a feature of professional practice. However, little is known about the processes through which social workers develop resilience or come to adopt a defensive stance in managing the demands of their work. This article focuses on professional storytelling among child welfare social workers. It examines how social workers to construct their professional role through team talk, and the implications of this for our understanding of professional resilience and defensiveness.

Drawing on an in-depth narrative analysis of focus groups with social work teams, eight story types are identified in social workers' talk about their work: emotional container stories, solidarity stories, professional epiphanies, professional affirmation stories, partnership stories, parables of persistence, tales of courageous practice and cautionary tales. Each story type foregrounds a particular aspect of child welfare practice, containing a moral about social work with vulnerable children and families. The article concludes with the implications of these stories for our understanding of both resilience and the pull towards defensiveness in child welfare social work.
\end{abstract}

\section{Introduction}

Stories actas a 'frame' for understanding ourselves and the world (Czarniawska, 2010: 61). Telling stories about our lives helps to render our experiences intelligible to ourselves and others (McAdams, 1993). Our stories often contain a 'moral' or a hard-won piece of learning that enables us to find meaning within a challenging experience. Storytelling has therefore been linked to resilience-our 
capacity to overcome adversity and learn from difficultexperiences (Eastet al, 2010). Stories may also serve a defensive function, allowing the individual to manage emotion by protecting and justifying the self. Thewaywe 'story' our lives, togetherwith the structure and omissions within ournarrative, can perform a repressive function, allowing us to block unacceptable or overwhelming experiences, emotion and thoughts from immediate awareness (Billig, 1997). Such stories may help us to cope with emotional challenges or threats to our sense of self, but we may be withdrawn, disengaged or defended in our response to others. This article focuses on the functions of storytelling among child welfare social workers. The emotional demands of child welfare social work have been welldocumented in the US (Travis, Lizano and Mor-Barak, 2016) the UK and Europe (Antonoupoulou et al, 2017; Mänttäri-van der Kuip, 2014) yet little is known about the processes through which resilience is constructedand maintained ineveryday practice. Theaim of this exploratory paperistoshed lighton these processes through examining storytelling in the context of focus groups. The stories, or 'team tales', generated in thesegroups enabled workers to construct aresilient sense of self, framing their experiences in a way that could help them to manage the emotional demands of the work and transmit this practice wisdom to colleagues. However, some stories appeared to serve a defensive function, representing risks for professional practice. This article offers some reflections on how storytelling might be important for understanding how to promote resilient, rather than defensive, cultures of practice in child welfare social work.

\section{Context}

It has been argued that child and family social work in England operates as a 'hybrid' system, combining family support services and child protection, and as such, is placed somewhere between the child protection focus of the U.S, and the family support service orientation of the Nordic countries, such as Norway and Finland (Gilbert et al 2011). The balance between family services and child protection in England and Wales is variable and highly contested (see Featherstone et al, 2014; 
Axford and Berry, 2018). Social workers have become the target of 'blame, hostility and anger' (Ruch et al, 2014: 318) following high-profile child death enquiries. This, combined with increased monitoring of risk and accountability, has increased demands placed on workers, creating 'powerful incentive for social workers engage in defensive practice' as means of protection against blame (Whittaker and Havard, 2016:1159). The Care Crisis Reviewin England and Wales(FRG, 2018)argued that the pendulum has swung further from support towards a more risk-averse, child protection orientation. Against this, however, there is a strong policy emphasis on early intervention, prevention and family support, with widespread uptake of strengths and relationship-based approaches to social work such as the 'Signs of safety' approach (SoS, 2018). Through the lens of professional storytelling, this article examines how social workers construct their professional role in this febrile policy context, and implications of this for our understanding of professional resilience and defensiveness.

\section{Professional storytelling}

Organisational researchers have identified professional storytelling as key to understanding the dynamics, culture and emotional experience of working life (Fineman, 1993) and the processes of learning and knowledge-transfer within organizations (Brown et al, 2009). Collecting naturallyoccurring and elicited stories is an established method forresearching organizations(seeCzarniawska, 2010). The structure of the stories told by professionals, including metaphor, plot and use of rhetorical techniques, can help us to understand organisational meaning-making (Tietze, Cohen and Musson, 2003). In Metaphors We Live By, Lakoff and Johnson (1980) argue that human cognition is underpinned by metaphor. Metaphor is defined as 'understanding and experiencing one thing in terms of another' (Lakoff and Johnson, 1980: 6). For instance, take the familiar metaphor 'time is money'. Like money, time can be spent, squandered, invested or borrowed. This way of seeing the world has implications for our social practices - we come to view time as a monetizable commodity. When studying work practices, collecting these 'metaphors of the field' (Tietze, Cohen and Musson: 
43) can tell us about the way professionals understand and experience their work. Drawing on the work of Lakoff and Johnson, Beckett (2003) analysed social workers' talk about their practice, drawing attention to themetaphor'social workaswar'. This metaphorprovidesaframeformaking senseof, and managing, the emotional experience of undertaking social work, a profession involving high levels of conflict and stress in a time-pressured environment. However, this metaphor also creates a way of seeing practice which focuses on the adversarial, rather than collaborative aspects of social work practice.

Within social work research there has been interest in the stories told by social workers about their work. Through a constructionist lens, social workers' stories are not regarded as providing a straightforward window onto practice - instead, such stories are regarded as constructed, negotiated and sustained through social interaction (Urek, 2005). Studies of social work practice have therefore examined the way that cases are constructed through collegial talk (e.g. Doherty, 2016). These stories are shaped by local cultures and frames of reference (Helm, 2013) and the wider discourses about social work identified above. Listening to social workerstalk abouttheirwork can provide insight into the formation of their professional identity (Wiles, 2012) and how they manage the emotional demands of their role (Forsberg and Vagli, 2006). Organisational learning involves the construction, telling and re-telling of stories between workers. For instance, Orr's (1996) seminal study of photocopier technicians demonstrated how local, specialised knowledge was transmitted from experienced to novice workers through the telling of 'war stories' - tales which reconstructed prior instances of overcoming difficulty in professional practice. These stories served to:

... preserve and circulate hard-won information and... make claims of seniority within the community. They also amuse, instruct, and celebrate the tellers' identity as technicians. (Orr, 1996: 126).

Similarly, Dingwall's (1977: 376) study of health visitors identified the telling of 'atrocity stories' in which the teller is positioned as brave protagonist, challenging other professionals: 
By casting occupation members as hero, atrocity stories maintain the intrinsic worth of the teller and, by implication, his colleague audience. Acquiring an appropriate repertoire of such stories and beingable to identifyappropriateoccasions fortelling themareimportantparts of being recognized as a competent member of an occupation...

Examining structure and language within professional storytelling can therefore provide insights into professional role, well as organisational culture and learning. However, despite the fact that peer support has been identified as promoting resilience (Biggart et al, 2017) there is relatively little empirical research examining how social workers share stories of their practice with each other. The present study addresses this gap, focusing on the function of shared storytelling in social work teams and the potential implications, and risks, of these stories for workers' practice with families.

\section{Methods}

The data for this analysis consists of two focus groups which were conducted as part of a wider project investigating social workers' experiences of undertaking home visits in the context of child welfare assessment. The interviews ( $n=18)$ focused on social workers' experiences of specific home visits (Cook, 2017). During these interviews, workers identified discussion with team colleagues as key to managing the demands of their work. A focus group methodology was therefore employed to examine the nature of the exchanges between team colleagues. Focus groups consist of a moderator facilitating a small group discussion, using 'the group process to stimulate discussion and obtain information on the beliefs, attitudes, or motivations of participants on a specific topic' (Linhorst, 2002: 209). In the present study, focus groups participants were invited to share their experiences of home visiting in the context of child welfare assessment. They were asked how they prepared for, and managed home visits, including the emotional demands of the work. 
Following approval from the University Ethics Committee, participants were recruited from Children's Services within two local authorities in England. Children are referred to these local authority services on the basis of perceived risk or need, and following initial screening, a social worker will typically undertake an initial assessment to determine the level of intervention required. Focus group one comprised workers from a single safeguarding team. This team undertook assessment work with families subject to child protection investigations as well as duty and initial assessments (where there was an immediate need to investigate concerns around abuse and neglect). The second focus group comprised four members of a single duty team. This team undertook initial assessments of cases referred from the local authority front-door referral screening service. Workers in this focus group were tasked with determining the level of need for services as well as determining the need to refer concerning cases to safeguarding teams.

\begin{tabular}{|l|l|l|l|l|}
\hline Focus & Team & Participants & Duration & Composition \\
\hline 1 & Safeguarding & 5 & & \\
\hline & team & & & \\
\hline 2 & Duty team & 4 & hour 57 minutes & 3 (male) \\
& & & & 3 (female) \\
\hline
\end{tabular}

Once discussion gained momentum, the groups required minimal facilitation. Workers discussed a range of topics, including their experiences of challenging encounters with children and families and how they conceived of, and managed, their role. This included sharing stories about their daily work together with memorable practice experiences that had changed them personally and professionally. The focus groups were lively and characterised by debate and humour. Workers were surprisingly 
open with the moderator about their emotional experiences and the challenges of their work. This is perhaps attributable to the perception of shared professional background between participants and the moderator; a researcher who had a social work background.

A key criticism of focus groups is the tendency towards 'groupthink' (McDougall and Baum, 1997); the tendency of participants to adjust their responses to conform to the views of the group. This desire for consensus can lead to errors in judgement and decision-making (Janis, 1972). In the present research, it is acknowledged that social workers may have adjusted their responses to preserve group cohesiveness. However, rather than viewing groupthink as a weakness of the data, the way that social workers reinforced and responded to each otherformed a crucial part of the data analysis itself. For instance, occasions of mutual reinforcement provided insight into how team members might achieve asense of shared roleorcollectiveidentity, as wellastherisksthatsuchgroup processesmightpose for practice e.g. in 'othering' professionals or service users (see 'solidarity stories' in section 2). In other instances, workers questioned their colleague's perspectives (see section 1) suggesting a tolerance of alternative viewpoints within the teams.

An audio recording was taken of each focus group. Following this, transcription was undertaken by the researcher. Data were analysed using a psychosocial narrative approach which recognises storytelling as a way for workers to generate meaning in relation to their practice (Czarniawska, 2010) while also acknowledging how the choice of story and its structure may act as a way to defend the telleragainstanxiety (Billig, 1997). Accordingly, attentionwas paidnotonly to whatwassaid, buthow it was said - the apparent omissions, structure and self-corrections in social workers' exchanges about their practice. Particular attention was paid to the identification of metaphors, together with individual and collective stories (Tietze, Cohen and Musson, 2003). Throughout the focus groups, workers told stories aboutspecific and pivotal moments of their work. Thesereconstructed snippets of practice, together with structure and use of language, were captured through line-by-line coding of the 207 minutes of transcribed dialogue. Coding focused on the specific language used by participants 
to describe cases, service users, practice and members of the team itself, as well as each occasion where social workers recalled a prior instance of practice. Following this, similar and overlapping codes were consolidated and re-labelled; instances of practice were grouped according to the 'moral' they conveyed about practice and recurring uses of instances of rhetorical techniques and metaphor were also grouped. This resulted in the distillation of eight key story types, reported below.

\section{Findings: 'Team tales' in child protection and duty social work}

The term 'team tales' is used to describe the stories that were told by workers individually and collectively in the focus groups. At an individual level, workers told stories about their own practice, often recalling experiences which contained a moral or lesson about the work. Workers also engaged in collectivestory-building, where members of the group built oneach other's narratives to presenta detailed picture of child welfare work. Eighttypes of 'team tale' were identified and will be presented in turn. Each includes a discussion of the potentially positive function of the story type alongside the potential risks for professional practice.

\section{Emotional container stories: absorbing and the need to 'vent'}

Throughout the first focus group, workers developed a specific metaphor to frame the emotional experience of undertaking child protection work. They described how theyacted as a 'container' for other people's emotions, including other professionals and service users:

SW3: I think we're like a sponge... you don't realise sometimes how it can build up and you can get saturated... I think it can slowly mount up, actually... like a cup, it can brim over and I think thatcancreepuponusassocialworkers. Becausewe absorbit. Unlessweusegood techniques to kind of get rid of it, where does it go? It can't go anywhere. 
Using Lakoff and Johnson's (1980) formulation, this metaphor can be expressed as 'emotions are water' and 'self is container'. Like water, emotions fill the container (the worker) and without an outlet, the container threatens to brim-over. Later in the focus group, the metaphor is picked up by another speaker:

SW1:I think we'reverygood atrecognising we've reached ourpeak and we can'ttake anymore! Getting really saturated, we need to drip it out somewhere else...

In this sense, emotions absorbed in the course of the work can leave the worker 'saturated' and in need of release. As the perceived pressure builds, the metaphor then develops - water becomes steam, and needs to be 'vented'. Talking to others in the team was then identified as having an important function in releasing pressure, since it:

SW5: ... lets you vent -

SW4: Yeah.

SW3: Mmm.

SW5: It lets you get it out of your system and it's 'Ah, I feel better for that now!'

SW2: Yeah!

SW3: Because that's what you do with families - you take it all!

Venting to one's colleagues was identified as a way to manage emotions - a way to empty the container(theworker) who could becomefull. 'Emotion as water' and 'self as container' provided an organising metaphor for team members, allowing them to articulate the shared emotional experience of the work. As workers described the process of venting they also demonstrated it in their exchanges. Forinstance, oneworkershared details of theirchallenging week with the team. Theyinturnshowed empathyand concern, allowing theworkertorelease some oftheirbuilt-upemotion. The conceptual 
metaphor 'self as container' implies that workers have a finite capacity to absorb and contain emotion. This suggests that unless there are opportunities to vent within organisations, workers may become saturated and unable to offer containment to families. The emotional container metaphor had an implicit message: this is difficult material to absorb and hold-in order to be managed, it needs to be shared.

However, while this metaphorwasusefulforexpressingand sharing theemotional reality of the work it could potentially have negative implications. For instance, one worker stated that venting to colleagues could be 'very politically incorrect' and 'offensive'. Venting in this sense appeared to involve inappropriate characterisations of service users. It is possible to envisage how this could foster an oppressive or cynical view of families. Most workers in the group did notappear comfortable with this characterisation of venting, describing it as being about sharing their personal reactions with colleagues, rather than expressing negative views about families. An interesting question, therefore, is whether there is a distinction between 'venting' and a more productive 'talking through' of difficulties to reach a resolution.

\section{Solidarity stories - us as different from them}

In both focus groups, workers articulated the unique aspects of their assessment-heavy roles by comparing themselves to other professions, and to other roles within the profession. These stories involved characterisation of the typical duty and safeguarding worker - a portrait of the type of person, theirqualities, skillsand characteristics-needed to performtherole. In relation todutywork, participants stated that:

SW6: It's a huge thing to do. I think there's real skill in that. I think we're lucky in our duty team, we're all - it's our thing.

SW8: Mm! 
SW6: I don't think you can work in a duty team unless it's yourthing. You have to have a low boredom threshold, I think (laughs) otherwise you'd want to carry on working with families all the timeand that would drive you insane. We've had people who have tried towork in duty and couldn't cope with only going in once or twice. And you've got to be really curious as people, and be willing to hear the whole life story from families and... work in a really quick way. Your brain has to work fast, as SW9 said, you're on your toes.

Characterising the 'type of worker' who would fit with the team served to emphasise the unique characteristics and skills of the team and its members. Specifically, workers identified a sense of vocation as anecessary criterionfor success in theteam, i.e. that dutysocial work needed to be 'your thing'. However, there is also the uncomfortable suggestion that long-term work with families is undesirable or 'madness'. These solidarity stories emphasised the endurance and shared skills of the collectiveteam, butinvolveda degree of 'othering' of both otherprofessionals and service users. For instance, those workers who could do assessment work were sharply contrasted to those who were perceived as not being up to the job:

SW4: Yeah, safeguarding and duty is specialist work -

SW5: Yeah.

SW4: - And if you can't do it, don't do it.

SW3: Yeah.

SW4: Don't come in and come into a team-because we-it'll burn you out, you'll leave a hole in our team which is more stress on the social workers that actually want to do it as a career. Social workers who think 'Oh, I need to do a year of that to get it on my CV' are just frustrating [to] me really. 
The purpose of these stories appeared to be to emphasise the team's unique identity in terms of skills and vocation, and to reinforce team membership by comparison to those workers who had tried, but who failed to go the distance. However, implicit in these tales is a cautionary message that if you don't fit or uphold the norms of the team you won't last. In this sense, there were echoes of Dingwall's (1977)atrocitystories, in whichworkers reaffirmed theirownidentity by telling derisorystories about other professionals (in this case, those who didn'tgo the distance, or those who wanted to work with families on a longer-term basis). While setting boundaries around timescales may be productive, there was an assumption that a preference for short-term work with families is necessarily a virtue. There is also the message that if you struggle, you will be a burdentoother 'career'social workers-and you shouldn't be in the team (If you can't do it, don't do it). Celebrating individual and collective professional skills is important, but it is also possible to imagine a how a problematic culture of bravado could develop, potentially preventing workers from seeking support. While professional pride is important, a 'them and us' view of other professionals and service users could be unhelpful for practice, potentially preventing communication with professionals outside of the team.

\section{Professional epiphanies- what I have learnt about myself as a social worker}

Workers provided short stories about a professional experience that had a lasting impact on them, shaping their sense of identity as a professional. Like Orr's (1996) war stories, these were characterised by a short, pithy example of practice - usually depicting a professional challenge, a particularly harrowing or emotional case. These experiences were presented by workers as transformative - they had learnt something fundamental about the work or about themselves as a professional:

SW6: It was one of those visits that everyone thinks of when they think about risky social work. It was 7 at night, nobody knew where I was. It was in the middle of nowhere... I know the manager was very concerned about it afterwards. But there was nothing to suggest that these grandparents were a risk beforehand... 
The worker then went on to describe a situation in which they had been threatened and held hostage in the house beforemanaging to escape to safety. The account was concluded with the moral of the story:

The family were not known to us previously - and now we're amazed that they weren't... And that's always the way - the risky visits in this business are the ones you can't see.

Before this incident, the worker had been relatively confident in their ability to manage challenging situations as she thought of herself as a 'seasoned and experienced' professional, and as such 'able to engage anyone'. However, the worker was changed by this frightening experience, recognising the inherent risks posed by the work. She now recognised her professional vulnerabilities and sought support rather than managing risk alone. Other professional epiphanies included experiences of being accused of a crime by a service user, experiencing assault and witnessing extreme cases of abuse and neglect.

Each of thesestories contained amoral, or important piece of learning about one's own practice and resilience, such as making peace with the fact that it is simply not possible to 'fix' things forevery child and family. Like Orr's (1996) war stories, these accounts allowed workers to articulate the development of their sense of professional identity and transmit learning to others in the team. For instance, the story recounted above represented an important piece of learning for the team as well as the worker; it led to detailed discussions about how measures could be put in place to improve worker safety.

However, not all professional epiphanies had positive outcomes. For instance, one worker described entering the profession feeling a desire to develop relationships with families and be 'liked'. However, a particularly challenging practice experience had led them to move from a position of openness in their work with families to a stance of 'expecting to be lied to.' Some professional experiences could lead to workers becoming more cynical or suspicious in relation to their work with families and arguably, the telling of such stories by experienced workers could shift perspective of other team 
members.

\section{Professional affirmation stories - this important work, society needs us}

Undertaking a high volume of initial and investigative visits meant that workers frequently encountered families who were understandably distressed at the prospect of social work visit. Workers described how, to managean initial home visit, they would need to marshal their emotional resources prior to entering the family home (see Author's Own, 2019). A way to do this was to generate affirmativenarratives aboutsocialwork as a profession-totellapositivestoryaboutsocial work and its role in society. This could act as a salutary reminder of the value of the work one was preparing to undertake. For instance, one worker described the need to call to mind that:

SW4:You are doing this because ... ninety-nine percent of society actually want you out there doing this job.

Drawing on the societal benefits of the profession acted as a way to affirm the positive purpose of the worker's current intervention. For instance, one worker told the following story of social work as a profession:

SW1: We're trying to break the cycle... get involved in the child's timescale, make those changes, get them on a path to where they can grow up as human beings who are responsible and respectful of others.

Reminding oneself of the importance of the role, and the wider benefits of their professional activity allowed workers to tolerate emotional challenges associated with a particular piece of work. Re-telling and holding on to positive stories was vital in countering negative stories about the profession:

SW6: The very nature of our role is to be is to be going out to risky families on our own - I think that's where our skill-base lies actually. The number of DV (domestic violence) cases we go out 
to without a second person, because we can manage people and their behaviours... And I think quiteoftenwe'revery goodatsaying what we're notverygood at and where we've failed. And I get really frustrated, like the Rotherham Report, Baby P, you know, any serious case review at any time, [we're] really good at berating ourselves, we're really not very good at looking at what we do right-

SW8: Ourstrengths!

SW6:Right!That'sthesocialworkway-let'sreflectand improve, butsometimes I think actually part of constructive reflection is looking at what worked, not just where we failed.

Celebratory stories of effective, supportive work with children and families is generally absent from wider societal narratives about the profession (LeGood et al, 2016), so collectively holding on to positive messages about the importance of social work in society is important for morale and potentially, for worker resilience. However, in foregrounding the role of the social worker in change, these stories tended to minimise the role of children and families themse/ves as active participants in the process ofchange.

\section{Partnership stories - find common ground and promote choice}

In contrast, some social workers' accounts of practice included stories that illustrated the importance of getting 'alongside' families. They spoke of the pressure, especially as an experienced worker, to feel solelyresponsiblefortheoutcomeofanintervention withafamily. Itwasthereforenecessarytokeep in mind that the work was about partnership, with the family taking an active role in bringing about positive change:

It's about that partnership thing - it's about partnership working. It's not me telling you, it's working together. When we're going to work together is if you're going to work with me. I... put 
my cards on the table and I expect you to put your cards on the table... we start to pave a way to work together. (SW7)

Workers recounted cases where getting alongside parents was key to bringing about a positive outcome. Key features of these partnership stories were a) establishing common ground and rapport and b) promoting parental choice:

SW1:Wehave a common link which is the children. Even the mostworrying offamilies actually want their children to thrive, even if they're not necessarily to enable that. If you bring it back to the kids much of the time that will help parents to come alongside. That's your common ground isn't it?

In these stories, working in partnership involved the social worker positioned as a promotor of choice:

What I always say to people is I'll advise you, I will give you the options but you make your choice. And it's like, ifyou makethe wrong choice, it could mean quite serious things happening to your children, being removed, but it's your choice. (SW4)

In theirstories of working in partnership with families, workers positioned parents as rational agents able to make choices. However, framing practice in this way de-emphasises the structural, and ecological factors (e.g. poverty, discrimination, gender etc.) which may have a bearing on parents' capacity to make choices in a meaningful way. Where partnership is more narrowly conceived as giving parents choice (as opposed to working together in a sustained way) there could be a sense of the social worker minimising their own professional role and responsibility in bringing about change through offering support, resources and encouragement.

\section{Parables of persistence - keep going, persistence pays off}


A key feature of social workers' daily practice was working with, and managing, resistance. However, repeated experiences of hostility from families could leave workers feeling dispirited and drained. A key aspect of professional resilience is the ability to manage the emotional demands of being rejected (see Author's Own, 2019) while resisting the temptation to 'shut down' or adopt a stance of 'detachment' (SW4). A parable is a 'succinct, didactic story, in prose or verse that illustrates one or more instructive lessons or principles' (OED, 2019). Social workers recounted short instances of practice where persistence and a willingness to tolerate initial rejection ultimately led to success. The moral of these parables appeared to be persistence pays off. Crucially, these stories contained a resolution, where the initial difficulty was overcome through persistence:

SW8: So I was sitting outside... a house... and we were being ranted at by a mother in the driveway. And each rant l'd sort of let her get it out of her system. l'd answer a bit, and anyway [she said] it's really late, you know, she's started changing you see. Anyway it's really late! Bla bla, you want to go home! Bla bla, and you'll want to have your tea! I would, I said, do you want to put the kettle on? And that was it! We completely laughed! So we went in, and then we could carry out theassessment.

In this instance, holding one's nerve and allowing service user to vent their anger is framed as a necessary step in achieving a meaningful and respectful relationship, indicated in the resolution of the story-going in for tea. The moral of this story seemed to be that persisting through initial rejection can pave the way for positive working relationships. Other workers provided examples where persistence was a professional virtue and could represent a powerful intervention in itself:

SW3: One of the ones that really got me the most was the ten-year-old boy-he hated me. He threatened me down the phone, hethreatened to punch me... He hated me so much because I removed him from his home, but he hated me up until the day I said to him look I'm going to hand this case over... He could say whatever he wanted to me, I mean he could do all sorts, he 
could threaten me... and l'd still be round there saying to him well, how do you feel about things?

The function of these stories seemed to be to promote courage and resilience in the face of difficulty as well as transmitting learning to others, i.e. that situations which begin badly can end well. However, these parables of persistence appeared to represent arisk. Asone worker pointed out, the pressure to feel that through hard work and persistence you can 'engage anyone' (SW5) can lead social workers to feel solely and personally culpable when intervention fails. The notion of persistence as a virtue mayalso mean that social workers feel pressure to tolerate unacceptable levels of risk to children or themselves in their attempts to engage service users. One worker, for instance, described how social workers frequently go into situations where all other professionals, including the police, would 'refuse' to attend.

\section{Stories of courageous practice-it's scary, butwe have the courage to protect children}

As the first responder to a concern around abuse or neglect, workers often witnessed distressing sights involving children. When asked how they managed these painful experiences, some workers constructed narratives which depicted the social worker as hero with the capacity to protect and save the child:

SW1: We're there for one reason, we're looking after children. We're protecting children. You can almost... treat it like a fantasy... charging over the hills on a white horse! ... Ultimately it's about rescuing the child, because pretty much what we're doing is rescuing children from very difficult positions.

These narratives depicted the social worker as a strong character, braving fraught and dangerous situations in a display of courage and heroism: 
SW4: Especially in the cases where there's been lots of big, aggressive figures in the family. You're the one that's gone in thereshowing I don'tcare! You can shoutand throw punches... whatever you want!l'msafeguarding this child!The child willseethatand thinkwell, I've been scared of this person, but this person has come in and stood up to them.

The idea of the social worker as hero, going into 'battle' (SW4), 'charging' over the hills (SW1) and 'bravely soldiering on' (SW6) in the face of adversity is reminiscent of Beckett's (2003) study, where practicewas defined bythemetaphor 'social workiswar'. Thinking of social workasgoing into 'battle' to save children helped workers to muster the courage and emotional resilience needed to manage upsetting situations and support children at risk. However, the positioning of the worker as hero, fighting for and rescuing the child foregrounds an adversarial approach to working with parents, which could create a defensive or oppressive dynamic.

\section{Cautionary tales: expect the unexpected and remain vigilant}

In the context of high-volume, time-limited assessment work, workers spoke of the fear that they would miss something, resulting in a vulnerable child being left at risk. Workers also repeatedly spoke of the discomfort and anxiety that accompanied the need to intrude into the private aspects of families'lives. Inorderto manage both this discomfortand toavoid complacency, workersneeded to strenuously call to mind the importance, and legitimacy, of being sometimes intrusive to protect children. To do this, workers evoked 'cautionary tales' - instances of prior practice (their own or a colleague's) which served to reiterate the necessity of their intrusion, remain vigilant and expect the unexpected:

SW3: We went into the house and it was an arranged visit, and the whole house was totally spotless. He [the father] says 'Ah, I'll show you round, and these are the children's bedrooms'.

Beds were made lovely, and... I said 'what's that room there, where's your room?' And he said 


\begin{abstract}
'oh, you can'tgo in there!'... I was like 'Weneed to go into this room!'It took about five minutes of negotiation... And he couldn't even open the door! He'd shoved everything in his house into that room - just horrendous! And I said to my student, see! That's why you've got to check every bedroom!
\end{abstract}

Thisstory has two keyfunctions. Firstly, itemphasises the need to remainvigilant to the possibility of 'hidden' risk and the need to sometimes be intrusive. Secondly, it distils a key piece of learning (you've got to check every bedroom) for new workers within the team - remain vigilant to the possibility of hidden risk. Other stories included instances where a worker 'looked in a cupboard and someone jumped out'(SW4) and where a family member became unexpectedly aggressive. However, while such cautionary tales might serve as a useful reminder to remain vigilant, there is also the risk that they could represent a 'policing' attitude towards families and a 'cynical mistrust' of parents on the part of workers (Woodhouse and Pengelly, 1991: 180). In the story above, for instance, there is an implicit message about needing to 'catch parents out'. However, hiding everything in one room may notnecessarily be dangerous or indicaterisk (it may, for instance, be more indicative of the parent's anxiety about the social worker's visit and efforts to please). There is perhaps a distinction to be made here between remaining legitimately vigilant and being mistrustful or suspicious of parents.

\title{
Discussion
}

Child welfare social workers undertake emotive work, managing need and risk in the context of reduced resources and increased caseloads (Travis et al, 2016; Mänttäri-van der Kuip, 2014). Organisational support (Antonopolou et al, 2017), particularly support from team colleagues (Biggart et al, 2017), can help workers to manage these demands. The findings from this explorative study provide insights into the formation of resilience - how shared 'team talk' and storytelling may help social workers to construct a robust sense of role, helping them to navigate and manage the demands 
of the work. At the same time, the findings also shed light on the risks of defensive coping in child welfare work.

Like the 'war stories' of Orr's (1991) photocopier technicians, the stories generated by social workers can be regarded as promoting professional resilience, celebrating and reaffirming workers' sense of their professional role while at the same time transmitting learning to colleagues in the team about how manage difficult practice experiences. Orr (1996: 139) observed that listening to the stories of experienced workers was 'part of the transformation of a new hire into a technician' providing messages to new team members about the sort of person they need to be. Similarly, the stories told in the focus groups were instructive, containing morals for practice such as the need for vigilance and partnership working. Storytelling was also used to explore and articulate workers' sense of professional role, such as what makes social work distinctive (solidarity stories) and the purpose of the individual social worker in working for the good of society (professional affirmation stories). Storying the work in certain ways appeared to allow the emotional challenges of the work to be managed. Parables of persistence and stories of courageous practice, for instance, appeared to support worker resilience by conveying optimistic messages about the ultimate value of the work, even in the face of difficulty.

However, some stories also appeared to represent a more defensive approach to coping with the demands of the work. By providing us with a frame, stories foreground particular features of experience while excluding and obscuring others. For this reason stories can block change within organisations (Boje, 1991) or transmit potentially defensive or 'ritualised ways of working' (White and Featherstone, 2005: 215). For instance, the metaphor of social work as war - evident in 'charging over hills' and 'standing up' to abusers emphasises conflict, positioning parents as adversaries. Similarly, cautionary tales employ a risk frame, foregrounding the tendency of parents to withhold the truth, ratherthan emphasising their positive qualities and strengths. Inforegrounding aspecificfeature of the child protection work, each of the stories also exclude other features. Each way of seeing practice 
has practice has potential benefits as well as risks. In relation to each of the eight story types, the following tensions can be distilled:

1. Being able to let out emotions within the team, without creating a derisory venting culture.

2. Celebrating and recognising social workers' distinctive professional skills, while avoiding an 'us and them' culture in relation to other professionals and service users.

3. Acknowledging the deep learning potential of 'career cases', while recognising the possibility that one might adopt a defensive position as result of these experiences.

4. Calling to mind the societal benefits and value of social work as profession, without losing sight of parents as active participants in change.

5. Building partnerships and promoting parental choice, while acknowledging the psychosocial factors that might impact on parents' capacity to make such choices.

6. Persisting with families in the face of lack of engagement or hostility without putting the child or oneself atrisk.

7. Retaining the professionalcourageneeded to protectchildren, whileavoiding an adversarial stance towards parents.

8. Remaining vigilantin relation to hidden risk, withoutbecoming cynical and 'policing' families. The tensions expressed in social workers' stories suggest there is a delicate balance to be maintained in sustaining a robust, yet non-defensive, sense of role as a child welfare social worker. Social workers' stories may also reflect the wider challenges of social work practice within a hybrid model, where there is an often uneasy relationship between child protection and family support (Featherstone et al, 2014).

The findings from this study suggest that stories told within social work teams may build resilience and promote effective coping strategies, but can also represent defensive, rather than constructive, adaptation in response to the demands of the work. Defensive practice has been described as social work's 'open secret', yet what it looks like in practice is seldom articulated (Whittaker and Havard, 
2016: 1160). Attention to the language and structure of professional storytelling sheds light on defensiveness - the way that practice is framed can help social workers to manage emotional challenges, butcan also lead to a sense of 'us and them' (Dingwall, 1977) in relation to both service users and otherprofessionals.

\section{Implications}

At an organisational level, attending to the stories told by workers could help managers to understand organisational behaviour and learning (Brown et al, 2009). Listening to 'team tales' may provide a way to make sense of, and potentially address, defensive team cultures. Since social workers share their professional epiphanies, an incident experienced by one worker may have a ripple effect throughout the team. There may therefore be a role for managers in helping workers to explore the collective learning from critical incidents as a team. Forsupervisors, helping social workers to re-frame, or 'restory' key instances of practices may be helpful in facilitating reflection as well as naming the pull towards defensive practice. For individual workers, the different types of 'team tale' identified in this study could providea framework forthinking abouttheirownsense of roleand resilience. Questions to consider could include: Which professional experiences have changed me as a worker? What are the dominant stories that I hear in my team, which stories am I drawn to and why? What stories do I tell myself to keep megoing in the work, and how do these influence my practice in both positive and negative ways?

The presentstudy has some limitations. Given the highlylocalised nature of the professionalstories captured in the data study (such as thefocus on high-volume assessment work) it is difficult to make generalisations about the role of storytelling in child welfare teams more widely. Similarly, the study cannotestablish how workers' stories and sense of roledirectlyimpacted their daily, directworkwith service users. However, this in-depth analysis of micro-storytelling suggests that professional storytelling has a crucial role to play in team culture and individual coping strategies; potentially 
reinforcing defensive frameworks for thinking, but also potentially establishing and maintaining much needed professional resilience among child welfare social workers.

\section{References}

Antonopoulou, A., Killian, M., and Forrester, D. (2017) Levels of stress and anxiety in child and family socialwork: workers' perceptions ororganizationalstructure, professionalsupportand workplace opportunities in Children's Services in the UK. Children and Youth Services Review, 76, 42-50.

Axford, N. and Berry, V. (2018) 'Perfect bedfellows: why early intervention can play a critical role in protecting children-a response to Featherstone et al (2014) 'A marriage made in hell: early intervention meets child protection" British Journal of Social Work, 48, 254-273.

Beckett, C. (2003) The language of siege: military metaphors in the spoken language of social work. British Journal of Social Work, 33, 625-639.

Biggart, L. Ward, E., Cook, L., Schofield, G. (2017) The team as a secure base: promoting resilience and competence in child and family social work. Children and Youth Services Review. 83, 119-130.

Billig, M. (1997) The dialogic unconscious: Psychoanalysis, discursive psychology and the nature of repression. British Journal of Social Psychology, 36, 2, 139-159.

Boje, D. (1991) The storytelling organization: astudy of story performance in an office-supply firm. Administrative Science Quarterly, 36, 106-126.

Brown, A., Gabriel, Y., Gherardi, S. (2009) Storytelling and change: an unfolding story. Organization, $16,3,323-333$.

Cook, L. (2017) Making sense of the initial home visit: the role of intuition in child and family social workers' assessments of risk. Journal of Social Work Practice, 31, 4, 431-444. 
Cook, L. (2019) The home visit in child protection social work: emotion as resource and risk for professional judgment and practice. Child and Family Social Work, 1-9, https://doi.org/10.1111/cfs. 12647

Czarniawska, B. (2010) The uses of narratology in social and policy studies. Critical Policy Studies, 4, $1,58-76$.

Doherty, P. (2016) Child protection threshold talk and ambivalentcase formulations in 'borderline' care proceedings cases. Qualitative Social Work, 16, 5, 698-716.

Dingwall, R. (1977) 'Atrocity stories' and professional relationships. Sociology of Work and Occupations, 4, 4, 371- 396.

East, L., Jackson, D. O'Brien, L., \& Peters, K. (2010). Storytelling: An approach that can help to develop resilience. Nurse Researcher, 17, 3, 17-25.

Featherstone, B., Morris, K. andWhite, S. (2014) 'A marriagemade in hell: early intervention meets child protection', British Journal of Social Work, 44: 1735-1749.

Fineman, S. (1993) (eds.) Emotion in Organizations. London: Sage.

Forsberg H., and Vagli, A. (2006)The social construction of emotions in child protection case-talk. Qualitative Social Work, 51, 1, 9-31.

FRG (2018) Care Crisis Review: Options for Change. London: Family Rights Group. FRG(2018b)Care Crisis Review:Professionals Survey Results. London: Family Rights Group. Gilbert, N., Parton, N. and Skivenes, M.(eds)(2011) Child Protection Systems: International Trends and Orientations, New York: Oxford University Press.

Helm, D. (2013)Sense-making in a social work office: an ethnographic study of safeguarding judgements. Child and Family Social Work, 21, 1, 26-35.

Janis, I. L. (1972). Victims of groupthink: A psychological study of foreign-policy decisions and fiascoes. Oxford, England: Houghton Mifflin.

Lakoff, M., and Johnson, G. (1980) Metaphors we live by. Chicago: Chicago University Press. 
Legood, A. McGrath., M. Searle, R. and Lee, A. (2016)Exploring how social workers cope with the public perception of their profession. British Journal of Social Work, 46, 7, 1872-1889.

Linhorst, D. (2002) A review of the use and potential of focus groups in social work research.

Qualitative Social Work, 1, 2, 208-228.

MacDougall, C. and Baum, F. (1997) The devil's advocate: A strategy to avoid groupthink and stimulate discussion in focus groups. Qualitative Health Research 7, 4, 532-541.

McAdams, D. (1993) The Stories We Live By:PersonalMythsand the Makingofthe Self. New York: Guilford Press.

Mänttäri-van der Kuip, M. (2014)The deteriorating work-related well-being among statutory social workers in a rigorous economic context. European Journal of Social Work, 17, 5: 672-688.

Orr, J. E. (1996) Talking about Machines: An Ethnography of a Modern Job. London: Cornell University Press.

Ruch, G., Lees, A., Prichard, J. (2014) Getting beneath the surface: scapegoating and the systems approach in a post-Munro world. Journal of Social Work Practice, 28, 3, 313-327.

Signs of Safety (2018) 'Signs of Safety continues to grow in England' https://www.signsofsafety.net/sofs-grows-in-england/ accessed 22.05.19.

Tietze, S., Cohen, L., and Musson, G(2003) Understanding organizations through Language. London: Sage.

Travis, D., Lizano, E., Mor-Barak, M. (2016) 'I'm so stressed!' A longitudinal model of stress, burnout and engagementamong social workers in child welfare settings. British Journalof SocialWork, 46, 1076-1095.

White, S. and Featherstone, B. (2005)Communicating misunderstandings: multiagency workas social practice. Child and Family Social Work. 10, 2, 207-216. 
Wiles, F. (2012) 'Not easily put into a box': constructing professional identity. Social Work Education, $32,7,854-866$.

Whittaker, A. and Havard, T. (2016) Defensive practice as 'fear-based' practice: social work's open secret? British Journal of Social Work, 46, 1158-1174.

Woodhouse, D. \& Pengelly, P. (1991) Anxiety and the Dynamics of Collaboration. Newcastle Upon Tyne: Aberdeen UniversityPress.

Urek, M. (2005) Making a case in social work. Qualitative Social Work, 4, 4, 451-467. 